\title{
АКТУАЛЬНЫЕ ПРОБЛЕМЫ ЗАКЛЮЧЕНИЯ ГРАЖДАНСКО-ПРАВОВЫХ ДОГОВОРОВ В ИНТЕРНЕТЕ
}

\section{ACTUAL PROBLEMS OF CONCLUDING CIVIL LAW CONTRACTS ON THE INTERNET \\ A. Gudkov \\ A. Krasilschikov \\ V. Mishchenko}

Summary: In this article, the authors analyze one of the current phenomena of civil turnover, which, with the development of digital technologies and the widespread use of the Internet, has firmly entered the life of society and is actively used by subjects of civil legal relations both in the business environment and in the field of solving social and everyday issues of citizens: the conclusion of civil law contracts on the Internet.

Noting the significant influence of information technology on the institution of contract law, the authors at the same time note problematic aspects in this area of legal relations. According to the authors, it requires additional legal regulation. On the basis of the analysis carried out, the authors express their proposals for amending the current legal mechanism of contractual relations and transactions.

Keywords: internet, contract, electronic form of contract, judicial practice, acceptance, offer, law, e-commerce, party.
Гудков Анатолий Иванович

К.ю.н., дочент, ВЮИ ФСИН России, gudkovaniv@yandex.ru

Красильщиков Анатолий Владимирович К.ю.н., дочент, ВЮИ ФСИН России

krasilschikov@inbox.ru

Мищенко Вячеслав Иванович

К.ф.н., дочент, ВЮИ ФСИН России,

vyacheslav-mischenko@mail.ru

Аннотация: В данной статье авторы анализируют одно из актуальных явлений гражданского оборота, которое с развитием цифровых технологий и широким использованием сети Интернет прочно вошло в жизнь общества и активно используется субъектами гражданских правоотношений как в предпринимательской среде, так и в сфере решения социально - бытовых вопросов граждан: заключения гражданско-правовых договоров в Интернете.

Констатируя существенное влияние информационных технологий на институт договорного права, авторы в то же время отмечают проблемные аспекты в данной сфере правоотношений. По мнению авторов, она требует дополнительного правового регулирования. На основе проведенного анализа авторы высказывают свои предложения по внесению изменений в действующий правовой механизм договорных отношений и сделок.

Ключевые слова: интернет, договор, электронная форма договора, судебная практика, акцепт, оферта, закон, электронная коммерция, сторона.

воров появилась и получила широкое распространение электронная форма фиксации договорных отношений.

Главной особенностью договоров, заключаемых в электронной форме, является взаимодействие их сторон посредством использования электронных средств связи, соответственно, согласование воли сторон происходит в бесконтактной форме, дистанционно.

Вместе с тем, в результате обзора научных источников по проблемам заключения электронного договора можно говорить о том, что в настоящее время в доктрине гражданского права отсутствует единообразное понимание сути электронного договора. Анализ гражданского законодательства показывает то же самое. Данное положение дел отражается как на истинном уяснении природы электронного договора, так и дифференциации таких договоров от классических договоров, понимание о которых уже устоялось в практике гражданского оборота. Другими словами, правовое регулирование сделок, заключенных в сети Интернет, разработано недостаточно: в правовой доктрине и в законодательстве отсутствует разграничение подобных договоров от традиционных, а также прописанная четкая процедура за- 
ключения договоров с использованием сети Интернет.

В научной литературе также отсутствует единое мнение по данному вопросу, в связи с чем можно встретить самые различные мнения по вопросам заключения гражданско-правовых договоров в Интернете и электронной коммерции.

Так, Т.Ю. Кулик под электронным договором предлагает понимать договор, заключенный в электронной форме [4. C. 14].

По мнению Н.А. Дмитрика обмен волеизъявлениями между сторонами происходит при помощи соответствующего технического и программного обеспечения, причем содержание волеизъявления передается не напрямую, а через посредников (информационных провайдеров) [3. С. 83].

Имеются и иные, порой противоречащие друг другу, позиции.

Обращаясь к положениям гражданского права РФ, отметим, что в настоящее время законодательно выделены две основные стадии заключения договора:

1. оферта - волеизъявление с предложением заключить договор на определенных условиях;

2. акцепт - волеизъявление противоположной стороны о готовности заключить договор на предложенных условиях.

Вышеуказанные стадии получили закрепление в ст. 432 ГК РФ [1]. Соответственно, выделяются также дополнительные стадии:

1. ведение переговоров о заключении договора (преддоговорная стадия);

2. уточнение условий договора и устранение разногласий (встречная оферта, или протокол разногласий).

Закономерно, что стадия оферты и стадия акцепта при заключении электронного договора также совершаются в электронной форме. При ведении переговоров о заключении такого договора субъекты правоотношений взаимодействуют дистанционно.

Особенности электронной формы гражданско-правового договора находят отражение в таких его разделах, как «Цена договора и порядок его оплаты» и «Адреса, реквизиты и подписи сторон». Поскольку оплата по договору может по соглашению сторон устанавливаться как в наличном, так и в безналичном порядке, в том числе путем денежного перевода с помощью электронных платежных систем (онлайн-банкинг, QIWI, PayPal и иные сервисы).
Кроме того, договор может быть подписан как классическим способом, так и с помощью электронной цифровой подписи (далее - ЭЦП).

В некоторых случаях законодательством РФ может быть установлена обязанность сторон подписать договор усиленной квалифицированной электронной подписью. В частности, например, это требуется для подписания контракта по результатам проведения электронной процедуры в рамках закупочной деятельности для государственных нужд.

Далее отметим, что для гражданско-правового договора законодательно сделана оговорка относительно формы его заключения. Нами имеется в виду п. 2 ст. 434 ГК РФ, в соответствии с которой договор в письменной форме может быть заключен путем составления одного документа (в том числе электронного), подписанного сторонами, или обмена письмами, телеграммами, электронными документами, иными данными.

То есть, приведенной нормой допускается заключение гражданско- правового договора в электронной форме. Указанное нами положение содержится в пункте, где речь идет о письменной форме договора, то есть, по сути законодателем обе эти формы приравниваются. Это, по нашему мнению, является не совсем верным, поскольку соблюдение формы договора играет существенную роль в последующих отношениях, складывающихся между сторонами заключенного договора, и может иметь далеко идущие юридические последствия в случае возникновения спора между сторонами.

Анализ судебной практики показывает, что, хотя электронная форма договоров приравнивается судами к письменной форме и электронные документы (включая сопроводительные документы к договору) принимаются ими при рассмотрении дел как вид доказательства по экономическим спорам, делают они это очень осторожно [2].

По нашему мнению, это является следствием того, что суды не готовы безоговорочно воспринимать электронную форму фиксации договорных отношений в связи с отсутствием непротиворечивого закрепления положений о такой форме договора в гражданском законодательстве РФ.

Отсутствие, либо несогласованность различных понятий, правовых категорий в нормативных правовых актах не позволяет судам в должной степени оценивать спорные ситуации, концентрироваться на единообразном разрешении гражданско-правовых (коммерческих) споров, вытекающих из договоров, заключенных посредством сети Интернет. 
Учитывая вышеизложенное, мы, безусловно, признаем востребованность электронной формы гражданскоправового договора, особенно учитывая общую санитарно-эпидемиологическую ситуацию во всем мире.

Но не следует забывать и о ряде проблемных моментов практического характера, поскольку они имеют юридические последствия. Так, например, контрагент может находиться в зарубежном государстве, а источник информации о нем может быть скрытым или недостоверным. Все это негативно влияет на процессы идентификации стороны договорных правоотношений и повышает риск заключения договора с недобросовестным контрагентом.

Данные обстоятельства в суде при рассмотрении спора могут выступать основанием для признания судом такого договора недействительным в связи с невоз- можностью установления стороны договорных правоотношений.

На основании изложенного и в целях унификации правоприменительной и судебной практики считаем целесообразным внести нижеследующие изменения и дополнения в положения ГК РФ.

1. Расширить п. 1 ст. 158 ГК РФ, изложив его в редакции, предполагающей совершение сделки и в электронной форме тоже. В частности, установить, что: «Сделки совершаются в устной, письменной (простой или нотариальной) или электронной форме».

2. Дополнить часть первую ГК РФ отдельной статьей, прямо предусматривающей возможность совершения сделки в электронной форме.

3. Дополнить ст. 434 ГК РФ положением, прямо предусматривающим электронную форму договора.

\section{ЛИТЕРАТУРА}

1. Гражданский кодекс Российской Федерации (часть первая) от 30.11.1994 N 51-Ф3 (ред. от 08.12.2020) // СЗ РФ. 1994. N 32. Ст. 3301.

2. Решение Абаканского городского суда Республики Хакасия от 25 мая 2017 г. по делу N 2-2198/2017 // СПС «Консультант Плюс».

3. Дмитрик Н.А. Осуществление субъективных гражданских прав с использованием сети Интернет. М., 2006. С. 83.

4. Кулик Т.Ю. Правовое регулирование договоров, заключаемых в электронной форме. М., 2008. С. 14.

\footnotetext{
( Гудков Анатолий Иванович (gudkovaniv@yandex.ru), Красильщиков Анатолий Владимирович (krasilschikov@inbox.ru),

Мищенко Вячеслав Иванович (vyacheslav-mischenko@mail.ru).

Журнал «Современная наука: актуальные проблемы теории и практики»
}

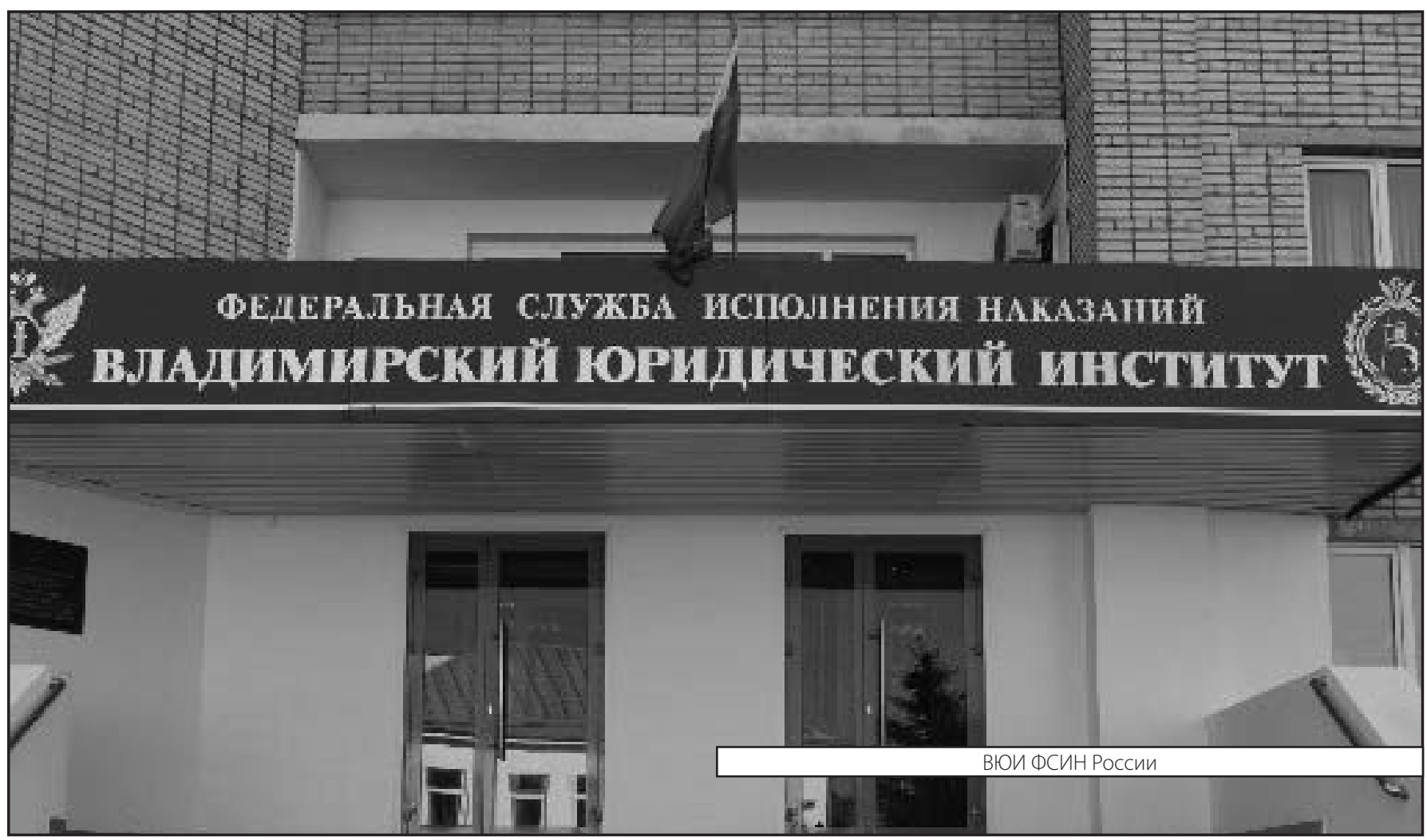

